\title{
IMPLEMENTASI FUZZY TSUKAMOTO DAN IOT PADA SISTEM PENDUKUNG KEPUTUSAN TINGKAT KEPADATAN LAHAN PARKIR
}

\author{
(Implementations of Fuzzy Tsukamoto and loT on a Decision Support Systems to \\ Determine Parking Density Level)
}

\author{
Indraning Tyas Adhitria*, Wirarama Wedashwara, Ahmad Zafrullah Mardiansyah \\ Program Studi Teknik Informatika, FT-UNRAM \\ JI. Majapahit 62, Mataram, Lombok NTB, INDONESIA
}

Email: adhitriatyas @gmail.com,wirawan@unram.ac.id, zaf@unram.ac.id

\begin{abstract}
Parking lots are a common thing in everyday life. Parking lot density can be a reference to find out how many people visit the place. So parking lot density level can be utilized by the owner of the parking lot to manage the place more efficient. For example, with knowing the density level of a parking lot, they can decide whether to open more parking lot or how many guards that must be placed. Most of the managers of a place know the density level of a parking lot by manually estimate it. If the system is developed with a more modern system, by providing information on the density of parking lots at a certain time, it will help managers in the process of parking lots management. So, this study aims to design a decision support system (DSS) to determine the density of parking lots by applying the concept of IoT and Tsukamoto's fuzzy method. The parking lot used for testing is in the form of a miniature car parking lot with a size $60 \mathrm{~cm} \times 70 \mathrm{~cm}$. loT is used for the automation of parking data collection. The data is used to create a fuzzy rule pattern using the Tsukamoto fuzzy method inference system. Tsukamoto's fuzzy logic will determine the density of the parking lot at the desired period. Based on testing the accuracy obtained by comparing the results of the calculation of fuzzy logic with a manual observation of 12 samples, an error of $8.11 \%$ was generated. The biggest error was generated from sample data on Monday. This is because Monday is the beginning of a system of calculating rule patterns, where the amount of data used to determine rule patterns is not as much as the following day.
\end{abstract}

Key words: Decision, Parking Lot, loT, Fuzzy Logic, Tsukamoto

*Penulis Korespondensi

\section{Pendahuluan}

Kendaraan bermotor merupakan kebutuhan yang sangat penting bagi kebanyakan masyarakat. Maka dari itu lahan parkir menjadi hal yang penting dalam kehidupan sehari-hari. Suatu tingkat kepadatan lahan parkir dari suatu tempat dapat menjadi masalah bagi pemilik suatu tempat. Kepadatan lahan parkir dapat menjadi acuan untuk mengetahui banyaknya orang yang mengunjungi tempat tersebut. Hal ini dapat dimanfaatkan oleh pemilik tempat untuk melakukan manajemen terhadap tempat yang dimilikinya tersebut. Saat ini kebanyakan pengelola suatu tempat hanya memperkirakan seadanya saja secara manual dalam mengetahui di waktu-waktu kapan lahan parkirnya padat atau sepi. Padahal dengan mengetahui tingkat kepadatan lahan parkir di waktu-waktu tertentu, pengelola tempat dapat lebih efisien dalam mengelola tempatnya. Pengelola dapat menggunakan keputusan tingkat kepadatan tersebut misalnya untuk menentukan luasnya halaman parkir yang dibuka, menentukan jumlah penjaga lahan parkir yang harus ditempatkan, atau jumlah pos parkir yang harus dibuka. Maka dari itu, jika sistemnya dikembangkan dengan sistem yang lebih modern, dengan memberikan informasi tingkat kepadatan lahan parkir pada periode tertentu maka akan sangat membantu pengelola dalam proses manajemen lahan parkir.

Perkembangan teknologi komunikasi wireless yang pesat saat ini memungkinkan dibuatnya suatu sistem yang dapat memantau objek secara otomatis. Banyaknya masyarakat yang menggunakan perangkat mobile yang terhubung ke internet membuat aliran data menjadi sangat cepat. Internet of Things (IoT) merupakan sebuah konsep yang bertujuan untuk memperluas manfaat dari konektivitas internet yang tersambung secara terus-menerus. IoT memungkinkan perangkat komputer secara otomatis dapat melakukan kontrol terhadap suatu sistem, dan memungkinkan pula untuk memberi aksi ke sistem terhadap kejadian yang terjadi pada sistem yang dikontrol secara real time [1].

Terdapat suatu konsep yang disebut Artificial Intelligence (AI) yang merupakan konsep di mana kecerdasan diciptakan dan dimasukkan ke dalam komputer agar dapat melakukan pekerjaan seperti yang dilakukan manusia. Salah satu bidang yang menggunakan Al yaitu adalah logika fuzzy. Logika fuzzy 
umumnya diterapkan pada masalah yang mengandung unsur ketidakpastian. Logika fuzzy dengan metode Tsukamoto merupakan metode yang fleksibel dan memiliki toleransi pada data yang ada. Kelebihan fuzzy Tsukamoto yaitu bersifat intuitif, diterima oleh banyak pihak, dan lebih cocok untuk input yang diterima dari manusia[2].

Berdasarkan penguraian di atas, maka akan dirancang sistem pendukung keputusan penentuan tingkat kepadatan lahan parkir pada periode tertentu untuk manajemen lahan parkir. Sistem yang dirancang terintegrasi dengan miniatur lahan parkir. Untuk mendapatkan data, digunakan konsep loT dengan menggunakan sensor ultrasonik yang dipasang untuk mengetahui jumlah kendaraan yang masuk dan keluar. Data tersebut digunakan sebagai penentuan aturanaturan dasar fuzzy untuk mendapatkan pola dari tingkat kepadatan lahan parkir berdasarkan variabelnya. Data sebagai variabel yang digunakan yaitu waktu, durasi lamanya tingkat kepadatan lahan parkir pada suatu periode, dan tingkat kepadatan lahan parkir. Hasil dari alur pola tingkat kepadatan lahan tersebut kemudian divalidasi dengan membandingkannya dengan keputusan secara manual oleh pikiran manusia

\section{Penelitian Terkait}

Sebelumnya sudah pernah dilakukan penelitian tentang penerapan konsep loT pada sistem parkir. Pada penelitian yang dilakukan oleh Rudi (2017), penerapan konsep loT pada sistem parkir digunakan untuk monitoring lahan parkir. Rudi menggunakan sensor ultrasonik HC-SRO4 untuk mendeteksi adanya suatu kendaraan pada selot parkir. Penelitian tersebut menggunakan Arduino UNO sebagai microcontroller yang terhubung dengan internet melalui chip Wi-Fi ESP8266. Melalui aplikasi bernama Blynk yang berbentuk website, user dapat mengetahui apakah selot parkir terisi oleh kendaraan atau tidak. Berdasarkan hasil uji coba yang dilakukan, diketahui bahwa sistem berfungsi dengan baik. Sensor ultrasonik dapat mendeteksi adanya kendaraan secara otomatis. Hasil keluaran berupa selot parkir terisi atau tidak juga ditampilkan pada website dan bekerja dengan baik. Namun Penelitian tersebut hanya menampilkan 3 buah selot parkir saja karena keterbatasan sensor[1].

Penelitian lainnya tentang penerapan loT pada sistem parkir dilakukan juga oleh Limantara, dkk (2017). Limantara membuat sebuah aplikasi sistem website untuk mendeteksi lot parkir yang kosong. Perangkat yang digunakan adalah sensor ultrasonik untuk mendeteksi kendaraan dan chip ESP8622 untuk transmisi data. Pada penelitian tersebut didapatkan bahwa sensor ultrasonik mampu mendeteksi keberadaan mobil dalam waktu kurang dari 10 detik. Dan untuk mengendalikan banyak chip ESP8366 lebih baik menggunakan perangkat data collections sehingga proses pengiriman data bisa lebih cepat[3]. Penerapan konsep loT sebelumnya sudah banyak digunakan untuk sistem parkir seperti penelitian yang pernah dilakukan oleh Atif[4], Rudi, dkk[5], dan Rao, dkk[6].

Penerapan metode fuzzy Tsukamoto untuk sistem pendukung keputusan sebelumnya pernah dilakukan oleh Mazenda, dkk (2104). Pada penelitiannya, Mazenda membuat sistem pendukung keputusan untuk menentukan kualitas air sungai dengan menerapkan metode fuzzy Tsukamoto. Aplikasi dibuat dalam bentuk sebuah website dengan pengujian data sebanyak 60 data. Penelitian tersebut menentukan apakah kualitas air sungai memenuhi baku mutu, tercemar ringan, tercemar sedang, atau tercemar berat. Berdasarkan pengujian menggunakan metode Black Box, persentase yang didapatkan adalah 100\% yang berarti sistem dapat berfungsi dengan baik. Dari 60 data yang diuji, 90\% terbukti kesesuaian hasil perhitungan menggunakan metode Tsukamoto dan metode STORET[7]. Fuzzy Tsukamoto sudah banyak digunakan untuk diimplementasikan pada sistem pendukung keputusan yang pernah dilakukan oleh Kaswidjanti[8], Mulyanto, dkk[9], Karya, dkk[10], dan Abdurrahman, dkk[11]

\section{Metodologi Peneltian}

\subsection{Alur Penelitian}

Alur dari jalannya penelitian ini dapat dilihat pada Gambar 1. Pada penelitian yang dilakukan, terdapat beberapa tahap untuk menyelesaikannya. Sesuai pada flowchart di atas, tahap untuk menyelesaikan penelitian ini yaitu menganalisis kebutuhan, merancang arsitektur sistem secara keseluruhan, merancang perangkat keras, database, dan perangkat lunak. Kemudian mengimplementasikan rancangan untuk kemudian diuji. Jika hasil pengujian menunjukkan sistem memenuhi fungsinya, maka dilanjutkan dengan dokumentasi dan laporan.

\subsection{Rancangan Arsitektur Sistem}

Rancangan arsitektur keseluruhan sistem yang dibuat dapat dilihat pada Gambar 2. Pertama, sensor ultrasonik akan mendeteksi adanya kendaraan yang masuk dan keluar. Kemudian mikrokontroller mengirim data tersebut ke web service untuk dilakukan perhitungan menggunakan metode fuzzy Tsukamoto sehingga menghasilkan aturan-aturan dasar fuzzy 
berbentuk IF-THEN. Kemudian user menggunakan sistem pendukung keputusan untuk menentukan tingkat kepadatan lahan parkir dalam bentuk website. Hasil keputusan didapatkan dari perhitungan dengan metode fuzzy Tsukamoto menggunakan aturan dasar yang didapat sebelumnya.

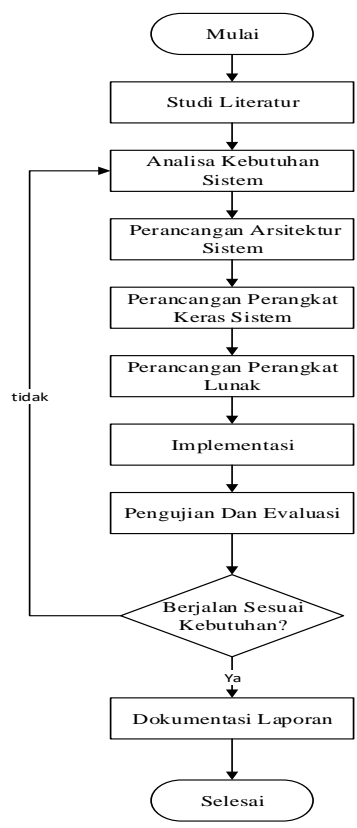

Gambar. 1. Flowchart alur penelitian

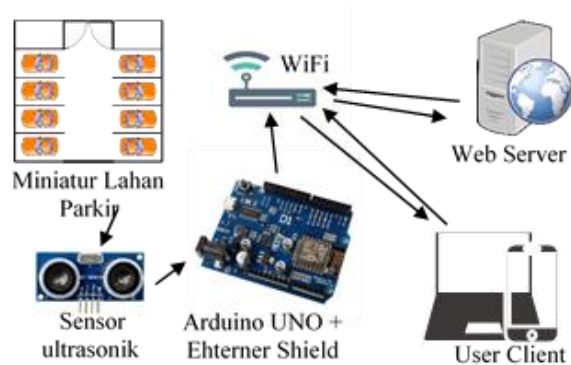

Gambar. 2. Rancangan Arsitektur Sistem

\subsection{Rancangan Perangkat Keras}

Rancangan Perangkat Keras dari sistem yang dibuat yaitu. Sensor ultrasonik diletakkan masing-masing pada jalur masuk dan keluar. Sensor terhubung dengan Arduino UNO sebagai mikrokontroller yang akan mengirim data ke server. Digunakan Ethernet Shield ESP8266 untuk menghubungkan Arduino UNO ke jaringan WIFI.

\subsection{Rancangan Perangkat Lunak}

\subsubsection{Perancangan Aplikasi Kontrol}

Rancangan aplikasi kontrol diimplementasikan di mikrokontroller (Arduino UNO). Alur pemrosesan data untuk dikirim ke server dapat dilihat di flowchart pada Gambar 3 di bawah ini:

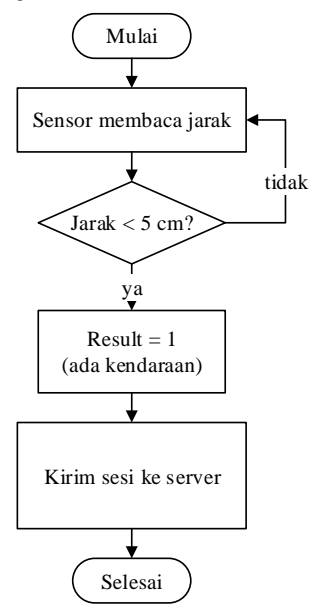

Gambar. 3. Flowchart aplikasi kontrol

\subsubsection{Metode Fuzzy Tsukamoto}

Secara umum terdapat tiga tahapan untuk menentukan tingkat kepadatan lahan parkir dengan metode inferensi fuzzy Tsukamoto, yaitu mendefinisikan variabel fuzzy (fuzzifikasi), inferensi, dan defuzzifikasi (menentukan output crisp).

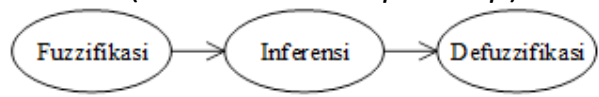

Gambar. 4. Tahap metode fuzzy Tsukamoto

Pada teori himpunan Fuzzy, peranan derajat keanggotaan sebagai penentu keberadaan elemen dalam suatu himpunan sangat penting[12]. Nilai keanggotaan menjadi ciri utama dari penalaran dengan Fuzzy Logic tersebut. Pada metode Tsukamoto, setiap aturan berbentuk IF-THEN dan harus dipresentasikan dengan suatu himpunan fuzzy dengan fungsi keanggotaan yang monoton[2].

Pada sistem yang akan dibangun, logika fuzzy akan melakukan pembelajaran berdasarkan data yang didapatkan dari konsep loT yang diterapkan pada lahan parkir. Perangkat loT akan mengambil nilai dari setiap variabel yang dibutuhkan, kemudian berdasarkan data tersebut logika fuzzy akan menentukan aturan fuzzynya. Aturan fuzzy dapat berubah sesuai dengan pola.

Berikut ini adalah contoh untuk menghitung nilai keanggotaan himpunan fuzzy dari salah satu variabel yaitu variabel kepadatan:

Variabel kepadatan terdiri dari 4 himpunan fuzzy, yaitu SEPI, SEDANG, RAMAI, dan SANGAT RAMAI. Fungsi untuk nilai keanggotaan himpunan fuzzy tersebut direpresentasikan pada Gambar 5. 


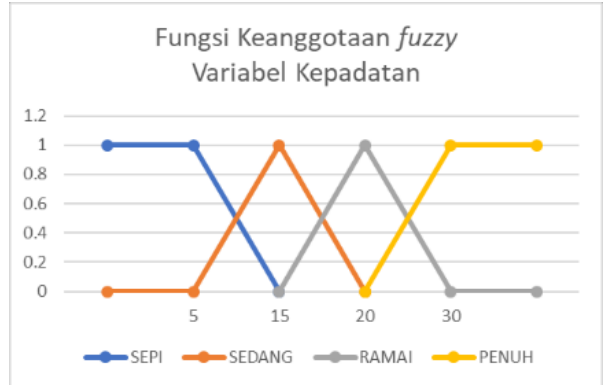

Gambar. 5. Grafik fungsi keanggotaan variabel kepadatan

Fungsi keanggotaan himpunan fuzzy SEPI dari himpunan fuzzy kepadatan adalah:

$$
\mu_{\text {kpdtSEPI }}[x]=\left\{\begin{aligned}
1, & x \leq 5 \\
\frac{15-x}{15-5}, & 5<x<15 \\
0, & x \geq 15
\end{aligned}\right.
$$

Fungsi keanggotaan himpunan fuzzy SEDANG dari himpunan fuzzy kepadatan adalah:

$$
\mu_{\text {kpdtSEDANG }}[x]=\left\{\begin{aligned}
0 & , x \leq 5 \\
\frac{x-5}{15-5}, & 5<x<15 \\
1, & x=15 \\
\frac{15-x}{20-15} & , 15<x<20 \\
0 & , x \geq 20
\end{aligned}\right.
$$

Fungsi keanggotaan himpunan fuzzy RAMAl dari himpunan fuzzy kepadatan adalah:

$$
\mu_{\text {kpdtRAMAI }}[x]=\left\{\begin{aligned}
0 & , x \leq 15 \\
\frac{x-15}{20-15}, & 15<x<20 \\
1, & x=20 \\
\frac{30-x}{30-20} & , 20<x<30 \\
0 & , x \geq 30
\end{aligned}\right.
$$

Fungsi keanggotaan himpunan Fuzy SANGAT RAMAI dari himpunan fuzzy kepadatan adalah:

$$
\mu_{\text {kpdtS.RAMAI }}[x]=\left\{\begin{aligned}
0 & , x \leq 30 \\
\frac{x-20}{30-20} & , 20<x<30 \\
1, & x \geq 30
\end{aligned}\right.
$$

Pada metode Tsukamoto, untuk menentukan output crisp, digunakan defuzifikasi rata-rata terpusat, yaitu:

$$
\mathrm{Z}=\frac{\sum_{1}^{i=n} \text { apredikat }^{*} \mathrm{Z}_{i}}{\sum \text { apredikat }}
$$

Untuk pengujian dilakukan dengan mengimplementasikan perangkat loT pada miniatur lahan parkir khusus mobil berukuran $60 \mathrm{~cm} \times 70 \mathrm{~cm}$. Data dari miniatur lahan parkir tersebut akan digunakan untuk melakukan proses inferensi fuzzy dengan metode
Tsukamoto untuk sistem pendukung keputusan yang dibuat.

\section{Hasil Dan Pembahasan}

\subsection{Hasil Implementasi}

Gambaran dari alur kerja sistem pendukung keputusan tingkat kepadatan lahan parkir yang dibangun pada penelitian ini dapat dijelaskan dengan tahapan sebagai berikut:

1. Perangkat IoT mendeteksi kendaraan yang masuk dan keluar di lahan parkir dengan menggunakan sensor ultrasonik.

2. Mikrokontroller Arduino UNO mengirim data sesi kendaraan di lahan parkir ke server dengan menggunakan WiFi.

3. Server menyimpan data sesi kendaraan di database.

4. Sistem berbasis website melakukan perhitungan fuzzy dengan metode Tsukamoto untuk menghasilkan pola aturan-aturan fuzzy.

5. User melakukan login pada website sistem pendukung keputusan tingkat kepadatan lahan parkir.

6. User memasukkan waktu yang diinginkan untuk mengetahui kepadatan lahan parkir pada saat waktu yang ditentukan tersebut.

7. Sistem akan melakukan perhitungan fuzzy untuk mendapatkan hasil keputusan kondisi lahan parkir pada waktu yang dimasukkan oleh user.

\subsubsection{Implementasi Perangkat Keras IoT}

. Kapasitas jumlah kendaraan pada alat yang dibuat yaitu sebanyak 30 buah mobil. Realisasi perangkat keras dari sistem dapat dilihat pada Gambar 6.

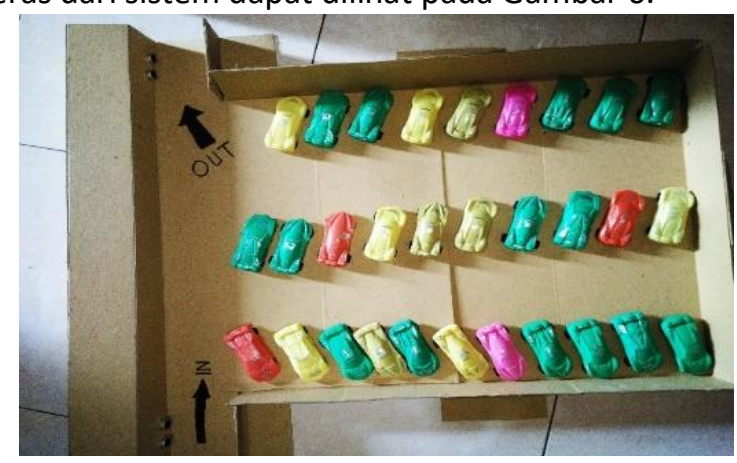

Gambar. 6. Tampilan keseluruhan alat

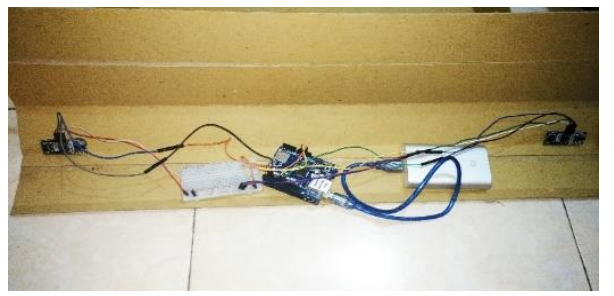


Gambar. 7. Tampilan perangkat IoT

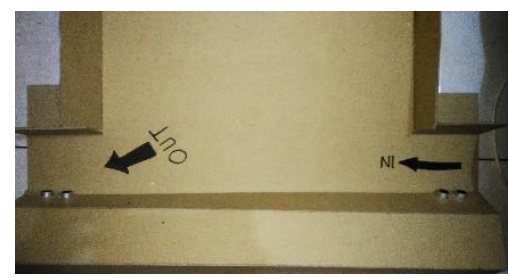

Gambar. 8. Tampilan sensor ultrasonik

Aplikasi kontrol dibangun pada mikrokontroller (Arduino UNO) untuk mengendalikan perangkat IoT agar bekerja sesuai fungsinya. Untuk pembuatan aplikasi kontrol, bahasa yang digunakan adalah bahasa C, dan IDE yang digunakan adalah Arduino IDE. Agar aplikasi kontrol dapat terkoneksi ke jaringan WIFI dan dapat mengakses web service, dibutuhkan suatu library tambahan. Library yang ditambahkan dapat dilihat pada source code dibawah ini:

\#include <ESP8266WiFiMulti.h>

\#include <ESP8266HTTPClient.h>

ESP8266WiFiMulti.h digunakan untuk mengakses WIFI sedangkan ESP8266HTTPClient.h digunakan untuk mengakses web service. Di bawah ini merupakan source code untuk menghubungkan Arduino ke jaringan Wi-Fi. Jaringan Wifi adalah nama WIFI yang akan dikoneksikan, sedangkan inipassword adalah kata sandi untuk terhubung ke Wi-Fi tersebut.

wifi.addAP("Jaringan Wifi”, "inipassword"; wifi.run();

Di bawah ini merupakan source code untuk mengakses web service. Http.begin digunakan untuk mendaftarkan URL yang akan diakses. Http.GET digunakan untuk mengakses URL dengan method GET.

http.begin("http://172.22.99.222:8080/loT/input_s esi/1 ");

data $=$ http.GET();

Di bawah ini merupakan source code untuk mendeteksi adanya kendaraan dengan sensor ultrasonik.

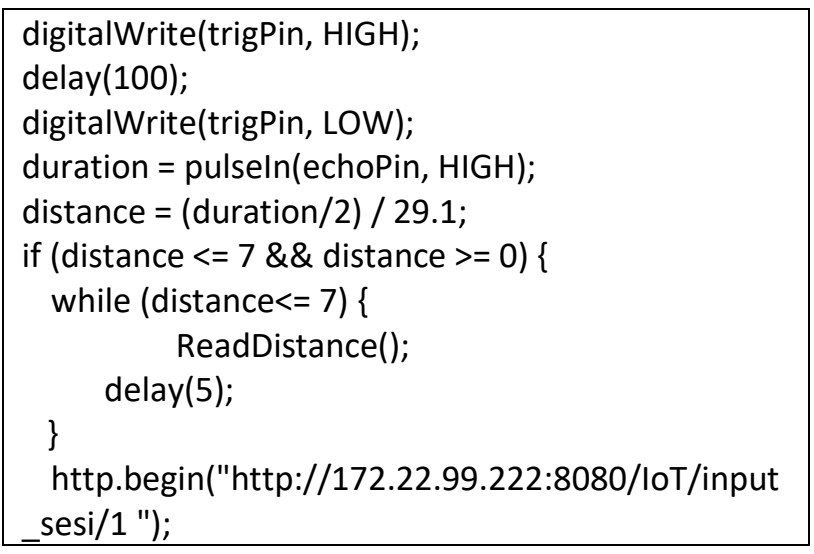

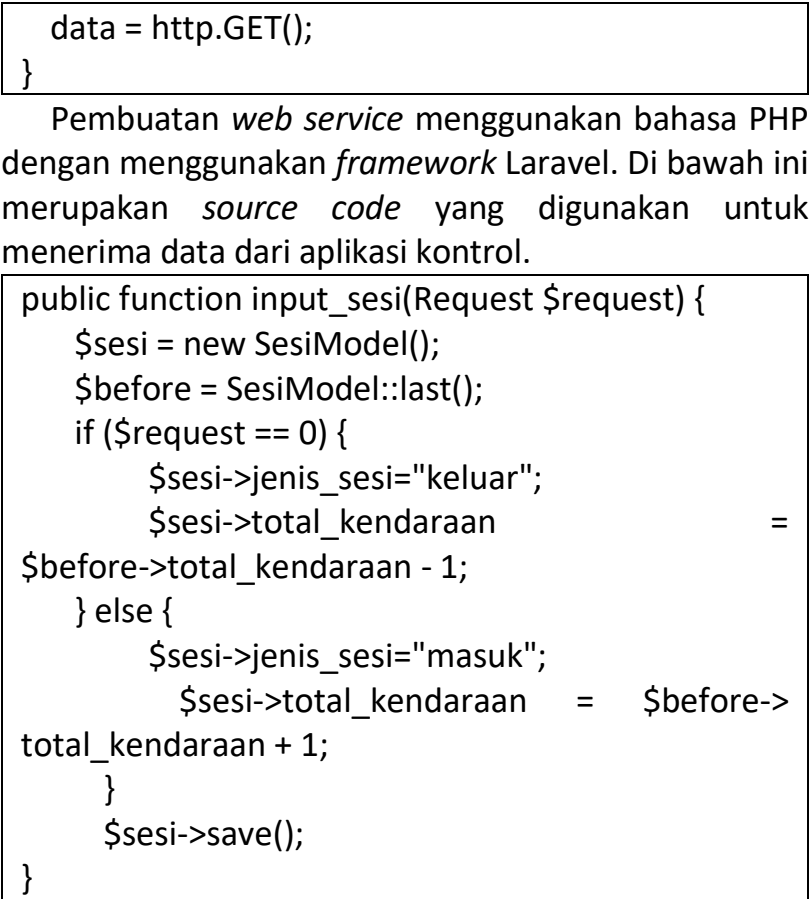

\subsubsection{Implementasi Metode Fuzzy Tsukamoto}

Metode Tsukamoto pada penelitian ini dibangun menggunakan bahasa PHP dengan framework Laravel. Skenario untuk penelitian ini yaitu terdapat sebuah lahan parkir yang memiliki kapasitas 30 buah mobil. Lahan parkir tersebut mulai beraktivitas pada pukul 9.00 pagi dan berhenti beraktivitas pada pukul 21.00 malam. Untuk tingkat kepadatan lahan parkir pada skenario ini, jika lahan parkir kosong maka tingkat kepadatan lahan parkir kosong. Jika total kendaraan pada lahan parkir adalah 30 buah, maka lahan parkir tingkat kepadatannya penuh. Jika total kendaraan kurang dari 12, maka tingkat kepadatan sepi. Jika total kendaraan di atas 24, maka tingkat kepadatan lahan parkir sangat ramai. Jika total kendaraan sekitar 12, maka tingkat kepadatan sedang. Jika total kendaraan sekitar 18, maka tingkat kepadatan ramai. Dihitung juga durasi untuk setiap state tingkat kepadatan. Yaitu durasi di mana lamanya suatu tingkat kepadatan tidak berubah. Jika durasinya kurang dari 30 menit, maka durasi kepadatannya sebentar. Jika durasinya antara 60-90 menit, maka durasi kepadatannya sedang. Jika durasinya antara 120 sampai 180, maka durasi kepadatannya lama. Dan jika durasinya di atas 210 menit maka durasi kepadatannya sangat lama.

Pada tahap ini, Metode Fuzzy akan diterapkan pada 2 jenis data yang berbeda, yaitu data dari perangkat IoT dan data input dari sistem pendukung keputusan.

Metode Fuzzy Tsukamoto Untuk Data Dari Perangkat IOT

Pada penelitian ini, perangkat loT akan membaca jika ada kendaraan yang masuk atau keluar yang disebut sesi. Waktu sesi adalah waktu saat data sesi 
dikirim dari perangkat IoT ke web service. Jenis sesi adalah tanda apakah ada suatu kendaraan masuk atau keluar. Total kendaraan adalah jumlah kendaraan saat ada sesi masuk atau keluar. Jika Jenis sesi adalah masuk, maka total kendaraan akan bertambah satu dari total kendaraan pada sesi sebelumnya. Sebaliknya jika jenis sesi adalah keluar maka total kendaraan sesi tersebut adalah total kendaraan sesi sebelumnya dikurangi satu. Durasi sesi adalah selisih waktu dari waktu sesi sebelumnya dengan sesi yang baru.

Pada Tabel I berikut ini adalah sebagian dari data yang diambil mulai hari Senin, 4 Februari 2019 sampai Rabu, 6 Februari 2019 oleh perangkat loT:

TABLE I. DATA SESI KENDARAAN DARI PERANGKAT IOT

\begin{tabular}{|c|c|c|c|c|}
\hline $\mathbf{n}$ & $\begin{array}{c}\text { Hari } \\
\text { sesi }\end{array}$ & $\begin{array}{c}\text { Waktu } \\
\text { sesi }\end{array}$ & $\begin{array}{c}\text { Total } \\
\text { Kend } \\
\text { araan }\end{array}$ & $\begin{array}{c}\text { Durasi } \\
\text { sesi } \\
\text { (menit) }\end{array}$ \\
\hline 0 & Senin & $9: 00: 00$ & 0 & 0 \\
\hline 1 & Senin & $9: 10: 00$ & 1 & 10 \\
\hline 2 & Senin & $9: 15: 00$ & 2 & 5 \\
\hline 3 & Senin & $9: 32: 00$ & 3 & 17 \\
\hline 4 & Senin & $10: 04: 00$ & 4 & 16 \\
\hline$\ldots$ & $\ldots$ & $\ldots$ & $\ldots$ & $\ldots$ \\
\hline 167 & Selasa & $14: 58: 00$ & 14 & 17 \\
\hline 168 & Selasa & $15: 16: 00$ & 15 & 18 \\
\hline 169 & Selasa & $15: 37: 00$ & 16 & 21 \\
\hline 170 & Selasa & $15: 45: 00$ & 17 & 8 \\
\hline$\ldots$ & $\ldots$ & $\ldots$ & $\ldots$ & $\ldots$ \\
\hline 287 & Rabu & $19: 33: 00$ & 9 & 10 \\
\hline 288 & Rabu & $19: 37: 00$ & 8 & 4 \\
\hline 289 & Rabu & $19: 47: 00$ & 7 & 10 \\
\hline 290 & Rabu & $19: 48: 00$ & 6 & 1 \\
\hline
\end{tabular}

Dari Tabel I di atas, dicari derajat keanggotaan dari variabel waktu dan hari.

Untuk variabel waktu, himpunan keanggotaannya terdiri dari Pagi, Siang, Sore, dan Malam. Fungsi keanggotaan variabel waktu untuk skenario ini dapat dilihat pada Tabel II

TABLE II. Fungsi KeAnggotaAn Variabel Waktu

\begin{tabular}{|l|l|l|l|}
\hline Waktu & $\begin{array}{l}\text { Representasi } \\
\text { Kurva }\end{array}$ & Domain & $\begin{array}{l}\text { Puncak } \\
\text { Domain }\end{array}$ \\
\hline Pagi & Bahu kiri & {$[9: 00,13: 00]$} & $9: 00$ \\
\hline Siang & Segitiga & $\begin{array}{l}{[9: 00, \quad 13: 00,} \\
17: 00]\end{array}$ & $13: 00$ \\
\hline Sore & Segitiga & $\begin{array}{l}{[13: 00, \quad 17: 00,} \\
21: 00]\end{array}$ & $17: 00$ \\
\hline Malam & Bahu Kanan & {$[17: 00,21: 00]$} & $21: 00$ \\
\hline
\end{tabular}

Untuk variabel kepadatan, himpunan keanggotaannya terdiri dari kosong, sepi, sedang, ramai, sangat ramai, dan penuh. Fungsi keanggotaan variabel kepadatan untuk skenario ini dapat dilihat pada Tabel III

TABLE III. Fungsi KeANGgotAAn VARIABEL KePADATAN

\begin{tabular}{|l|l|l|c|}
\hline $\begin{array}{l}\text { Tingkat } \\
\text { Kepadatan }\end{array}$ & $\begin{array}{l}\text { Representasi } \\
\text { Kurva }\end{array}$ & Domain & $\begin{array}{l}\text { Puncak } \\
\text { Domain }\end{array}$ \\
\hline Kosong & Tegak lurus & {$[0]$} & 0 \\
\hline Sepi & Bahu kiri & {$[6,12]$} & 6 \\
\hline Sedang & Segitiga & {$[6,12,18]$} & 12 \\
\hline Ramai & Segitiga & {$[12,18,24]$} & 18 \\
\hline Sangat Ramai & Bahu Kanan & {$[18,24]$} & 24 \\
\hline Penuh & Tegak lurus & {$[30]$} & 30 \\
\hline
\end{tabular}

Untuk variabel durasi kepadatan, himpunan keanggotaannya terdiri dari Sebentar, Sedang, Lama, dan Sangat Lama. Fungsi keanggotaan variabel durasi kepadatan untuk skenario ini dapat dilihat pada Tabel IV

TABLE IV. Fungsi KeANggotaAn VARIAbel DuRASI KEPADATAN

\begin{tabular}{|l|l|l|c|}
\hline $\begin{array}{l}\text { Durasi } \\
\text { Kepadata } \\
\mathbf{n}\end{array}$ & $\begin{array}{l}\text { Representa } \\
\text { si Kurva }\end{array}$ & Domain & $\begin{array}{l}\text { Puncak } \\
\text { Domai } \\
\mathbf{n}\end{array}$ \\
\hline Sebentar & Bahu kiri & {$[0,30,60]$} & $0-30$ \\
\hline Sedang & Trapesium & {$[30,60,90,120]$} & $60-90$ \\
\hline Lama & Trapesium & {$[90,120,180,21$} & $\begin{array}{c}120- \\
180\end{array}$ \\
\hline $\begin{array}{l}\text { Sangat } \\
\text { lama }\end{array}$ & Bahu Kanan & {$[180,210,270]$} & $\begin{array}{c}210- \\
270\end{array}$ \\
\hline
\end{tabular}

Untuk membuat himpunan fungsi keanggotaan dari masing-masing variabel seperti pada Tabel II, Tabel III, dan Tabel IV maka dibuat kategori dengan source code di bawah ini:

\begin{tabular}{|l|}
\hline addCategory('waktu')-> \\
addMembership('PAGI',[9,9,13])-> \\
addMembership('SIANG', $[9,13,17])->$ \\
addMembership('SORE', $[13,17,21])->$ \\
addMembership('MALAM', [17,21,21])->;
\end{tabular}

AddCategory merupakan fungsi yang dibuat untuk menyimpan variabel dengan parameter nama variabel tersebut. AddMembership merupakan fungsi yang dibuat untuk memberi nilai himpunan fungsi keanggotaan. Perhitungan yang dilakukan oleh fungsi addMembership dapat dilihat pada source code di bawah ini:

\$a = \$this $->$ parameter[0];

$\$ b=\$$ this $->$ parameter[1]; 
\$c = \$this $->$ parameter[2];

return $\max (\min ((\$ x-\$ a) /(\$ b-\$ a),(\$ c-\$ x) /(\$ c-$

\$b) ),0);

Dari source code di atas, maka akan didapatkan nilai keanggotaan $(\mu)$ dari masing-masing himpunan keanggotaan. Nilai keanggotaan tersebut digunakan untuk tahap selanjutnya yaitu inferensi.

Hasil metode Tsukamoto untuk data loT bentuk per kelasnya akan menjadi seperti pada Tabel $\mathrm{V}$ berikut ini

TABLE V. DATA PER KeLAS

\begin{tabular}{|l|l|l|l|l|}
\hline $\mathbf{N}$ & Hari & Waktu & $\begin{array}{l}\text { Rata-rata } \\
\text { Total } \\
\text { Kendaraan }\end{array}$ & $\begin{array}{l}\text { Durasi } \\
\text { Kepadatan } \\
\text { (menit) }\end{array}$ \\
\hline 1 & Senin & Pagi & 4.5 & 101 \\
\hline 2 & Senin & Siang & 17.93 & 240 \\
\hline 3 & Senin & Sore & 20.5 & 256 \\
\hline 4 & Senin & Malam & 18.05 & 132 \\
\hline 5 & Selasa & Pagi & 6.64 & 100 \\
\hline 6 & Selasa & Siang & 9.88 & 265 \\
\hline 7 & Selasa & Sore & 23.59 & 527 \\
\hline 8 & Selasa & Malam & 11.5 & 253 \\
\hline 9 & Rabu & Pagi & 4.50 & 118 \\
\hline 10 & Rabu & Siang & 15.93 & 233 \\
\hline 11 & Rabu & Sore & 23.21 & 242 \\
\hline 12 & Rabu & Malam & 6.94 & 127 \\
\hline
\end{tabular}

Dari Tabel $\mathrm{V}$ di atas, dihitung semua keanggotaan dari variabel Total Kendaraan dan Durasi Kepadatan. Maka akn didapatkan aturan basis seperti pada Tabel VI berikut.

\subsubsection{Metode Fuzzy Tsukamoto Untuk Sistem Pendukung Keputusan}

Pada penelitian ini, user akan menginput waktu yang diinginkan untuk mengetahui tingkat kepadatan dan durasi kepadatan pada lahan parkir sesuai dengan waktu yang diinginkan. Contohnya terdapat skenario seorang user ingin mengetahui tingkat kepadatan pada hari Senin pukul 20:15. Maka tahap perhitungan yang dilakukan adalah sebagai berikut:

$x=20+\left(\frac{15}{60}\right)=20,25$ maka $x>17$ dan $x<21$

$\mu_{P A G I}[x]=0, \quad x \geq 13$

$\mu_{S I A N G}[x]=0, x \geq 17$

$$
\begin{aligned}
\mu_{\text {Sore }}[x] & =\frac{21-x}{21-17} \quad, \quad 17<x<21 \\
& =\frac{21-20,25}{4}=0,19
\end{aligned}
$$

$\mu_{\text {malam }}[x]=\frac{x-17}{21-17}, 17<x<21$

$$
=\frac{20,25-17}{4}=0,81
$$

$\mu$ waktu $=\max (0 ; 0 ; 0,19 ; 0,81)=0,81 \rightarrow$ Malam
TABLE VI. HASIL KELOMPOK VARIABEL DENGAN FUZZY

\begin{tabular}{|c|c|c|c|c|}
\hline $\mathbf{n}$ & Hari & Waktu & $\begin{array}{c}\text { Tingkat } \\
\text { Kepadatan }\end{array}$ & $\begin{array}{c}\text { Durasi } \\
\text { Kepadatan }\end{array}$ \\
\hline 0 & Senin & Pagi & Sepi & Sedang \\
\hline 1 & Senin & Siang & Ramai & Sangat Lama \\
\hline 2 & Senin & Sore & Ramai & Sangat Lama \\
\hline 3 & Senin & Malam & Ramai & Lama \\
\hline 4 & Selasa & Pagi & Sepi & Sedang \\
\hline 5 & Selasa & Siang & Sedang & Sangat Lama \\
\hline 6 & Selasa & Sore & Sangat Ramai & Sangat Lama \\
\hline 7 & Selasa & Malam & Sedang & Sangat Lama \\
\hline 8 & Rabu & Pagi & Sepi & Lama \\
\hline 9 & Rabu & Siang & Ramai & Sangat Lama \\
\hline 10 & Rabu & Sore & Sangat Ramai & Sangat Lama \\
\hline 11 & Rabu & Malam & Sepi & Lama \\
\hline 12 & Senin & Pagi & Sepi & Sedang \\
\hline
\end{tabular}

Kemudian untuk mendapatkan nilai tingkat kepadatan dan durasi kepadatannya, digunakan metode fuzzy tsukamoto dengan perhitungan masing-masing aturan. Aturan yang digunakan merupakan aturan dari kelas hari Senin yaitu:

[R1] IF hari SENIN AND waktu PAGI THEN kepadatan SEPI AND durasi kepadatan SEDANG

$\alpha$-predikat kepadatan $1=\mu_{P A G I}=0$

$\mathrm{Z}_{\text {kepadatan } 1}=0$

$\alpha$-predikat durasi1 $=\mu_{P A G I}=0$

$\mathrm{Z}_{\mathrm{drasi} 1}=0$

[R2] IF hari SENIN AND waktu SIANG THEN kepadatan RAMAI AND durasi kepadatan SANGAT LAMA

$\alpha$-predikat kepadatan2 $=\mu_{\text {SIANG }}=0$

$\mathrm{z}_{\text {kepadatan2 }}=0$

$\alpha$-predikat durasi2 $=\mu_{\text {SIANG }}=0$

$\mathrm{z}_{\mathrm{drasi} 2}=0$

[R3] IF hari SENIN AND waktu SORE THEN kepadatan RAMAI AND durasi kepadatan SANGAT LAMA $\alpha$-predikat kepadatan3 $=\mu_{\text {SORE }}=0,19$

$z_{\text {kepadatan3-1 }}=(6 * 0,19)+12=13,14$

$Z_{\text {kepadatan3-2 }}=24-(6 * 0,19)=22,86$

$Z_{\text {kepadatan } 3}=\operatorname{MAX}(12,14 ; 22,86)=22,86=23$

$\alpha$-predikat durasi3 $=\mu_{\text {SORE }}=0,19$

$z_{\text {durasi3 }}=210-(30 * 0,19)=204,3$ menit

[R4] IF hari SENIN AND waktu MALAM THEN kepadatan RAMAI AND durasi kepadatan LAMA

$\alpha$-predikat kepadatan $4=\mu_{M A L A M}=0,81$

$\mathrm{z}_{\text {kepadatan } 4-1}=(6 * 0,19)+12=28,86$

$Z_{\text {kepadatan4-2 }}=24-\left(6^{*} 0,19\right)=7,14$

$Z_{\text {kepadatan } 4}=\operatorname{MAX}(28,86 ; 7,14)=28,86=29$

$\alpha$-predikat durasi4 $=\mu_{M A L A M}=0,81$

$\mathrm{z}_{\text {durasi4-1 }}=(30 * 0,81)+90=234,3$

$Z_{\text {durasi4-2 }}=210-(30 * 0,81)=65,7$

$Z_{\text {durasi4 }}=\operatorname{MAX}(234,3 ; 65,7)=234,3$ menit 
$Z^{*}{ }_{\text {- kepadatan }}=(0,19 * 23)+(0,81 * 29) / 0,19+0,81=$ $27,86=28$ buah kendaraan

$x=28$ maka $x \geq 24$

$\mu_{\text {kosong }}[x]=0, \quad 0 \neq x$

$\mu_{\text {Sepi }}[x]=0, \quad x \geq 12$

$\mu_{\text {Sedang }}[x]=0 \quad, \quad x \geq 18$

$\mu_{\text {ramai }}[x]=0, \quad x \geq 24$

$\mu_{\text {Sangat Ramai }}[x]=1, \quad x \geq 24$

$\mu_{\text {penuh }}[x]=0, \quad x \neq 30$

$\mu$ kepadatan $=\max (0 ; 0 ; 0 ; 0 ; 1 ; 0)=1$

$$
\rightarrow \text { Sangat Ramai }
$$

$Z^{*}$ - durasi kepadatan $=(0,19 * 204,3)+(0,81 * 234,3) / 0,19+$ $0,81=228,6$ menit

$x=228,6$ maka $x \geq 210$

$\mu_{\text {SEBENTAR }}[x]=0, \quad x \geq 60$

$\mu_{S E D A N G}[x]=0, \quad x \geq 120$

$\mu_{L A M A}[x]=0, \quad x \geq 210$

$\mu_{\text {SANGAT LAMA }}[x]=1, \quad x \geq 210$

$\mu$ durasi kepadatan $=\max (0 ; 0 ; 0 ; 0 ; 1)=1$

$$
\rightarrow \text { Sangat Lama }
$$

Jadi, untuk input hari Senin pukul 20:15, tingkat kepadatannya yaitu sangat ramai dengan total kendaraan sebanyak 28 buah kendaraan, dan durasi kepadatan sangat ramai tersebut berlangsung dalam waktu yang sangat lama yaitu 228,6 menit

\subsubsection{Implementasi Sistem Pendukung Keputusan}

Implementasi sistem pendukung keputusan tingkat kepadatan lahan parkir dibuat dalam bentuk website. Sistem dibuat menggunakan bahasa PHP dengan framework Laravel dan Bootstrap.

\section{a. Halaman Log In}

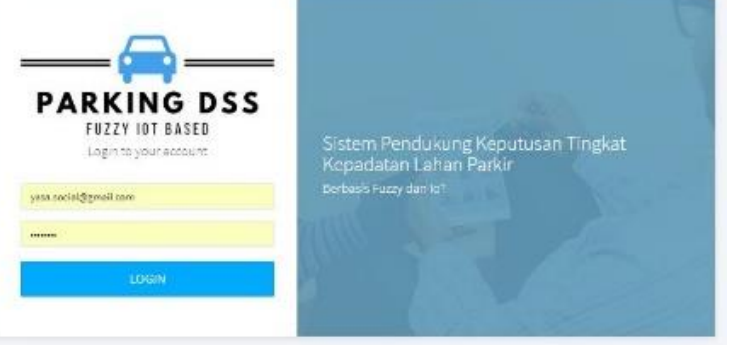

Gambar. 9. Tampilan halaman login

Pada halaman tersebut, user akan memasukan email dan password untuk dapat mengakses sistem pendukung keputusan tingkat kepadatan lahan parkir yang dibuat.

\section{b. Halaman Dashboard}

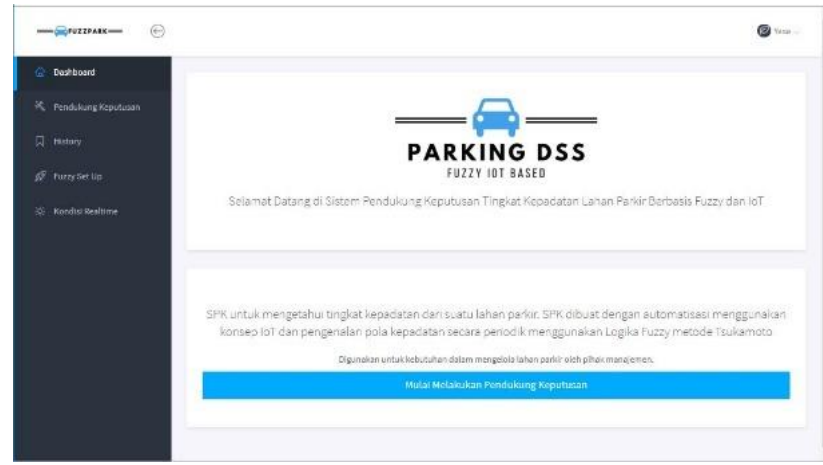

Gambar. 10. Tampilan halaman dashboard

Pada halaman dashboard seperti pada Gambar 10, terdapat informasi tentang apa saja yang dapat dilakukan pada sistem pendukung keputusan tingkat kepadatan lahan parkir yang dibuat.

\section{c. Halaman Pendukung Keputusan}

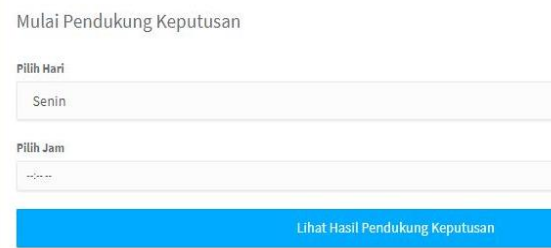

Gambar. 11. Tampilan halaman pendukung keputusan

Pada halaman pendukung keputusan seperti pada Gambar 11, terdapat form untuk menginput nilai variabel yatu hari dan jam. Kemudian jika tombil lihat hasil keputusan di klik setelah mengisi form input, maka akan menuju halaman hasil keputusan yang merupakan hasil perhitungan metode fuzzy untuk mengetahui tingkat kepadatan lahan parkir

\section{d. Halaman Hasil Keputusan}

Result

Pada senin jam 11:34, jumlah kendaraan yang biasanya ada di lahan parkir yaitu 15 kendaraan durasi kepadatan lahan parkir pada kondisi tersebut selama 105 menit. Lahan parkir pada senin siang tidak terlalu padat ataupun sepi dalam durasi yang cukup lama

Gambar. 12. Tampilan halaman hasil keputusan

Pada halaman hasil keputusan seperti pada Gambar 12 , terdapat informasi hasil dari proses pendukung keputusan berdasarkan waktu input yang dimasukan oleh user. 


\section{e. Halaman Pola Kepadatan}

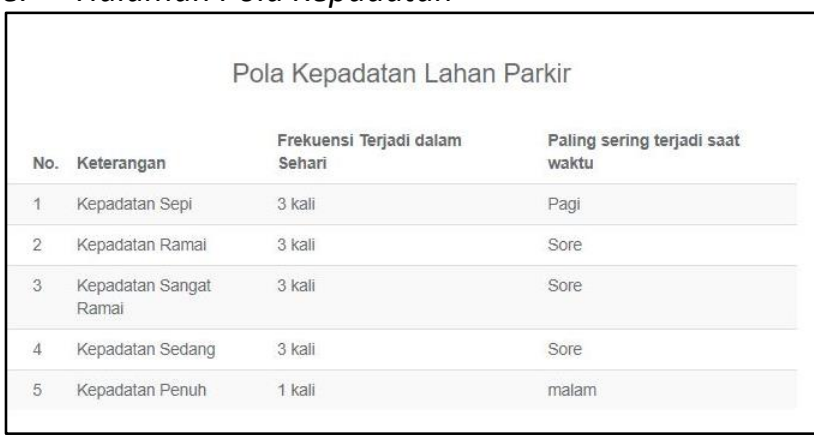

Gambar. 13. Tampilan halaman kepadatan

Pada Gambar 13, merupakan halaman untuk melihat pola kepadatan lahan parkir. User dapat mengetahui seberapa sering pola kepadatan terjadi. Contohnya yaitu untuk satu hari, tingkat kepadatan sepi terjadi sebanyak 3 kali dan paling sering terjadi pada waktu pagi hari.

\section{f. Halaman Lihat Rule Base}

\section{Fuzzy Rule Base}
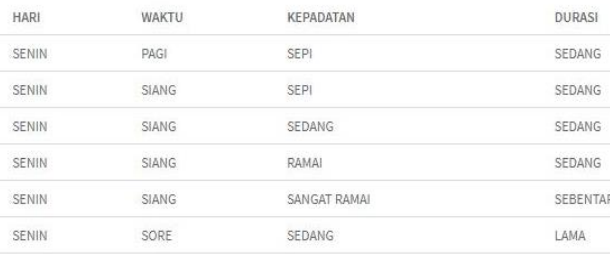

Gambar. 14. Tampilan halaman lihat rule base

Pada halaman ini, user dapat melihat aturan-aturan yang digunakan untuk menghitung nilai keanggotaan dan inferensi pada metode fuzzy tsukamoto. Contohnya yaitu pada Senin pagi, tingkat kepadatan biasanya sepi untuk durasi yang sedang.

\section{g. Halaman History}

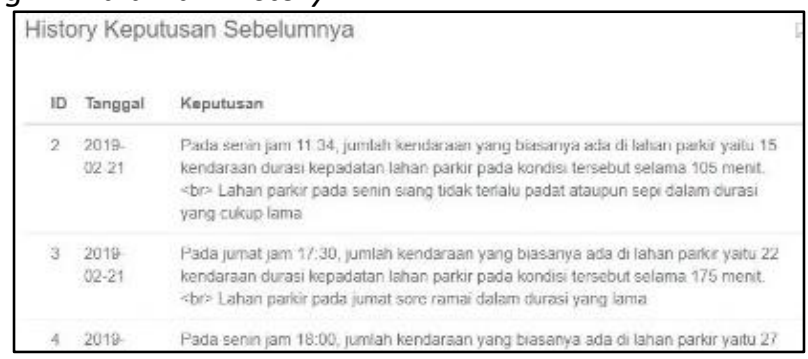

Gambar. 15. Tampilan halaman history

Pada halaman ini, user dapat melihat hasil keputusan sebelumnya. Seperti pada Gambar 15, informasi yang ditampilkan adalah tanggal dan hasil keputusan sebelumnya.

\section{h. Halaman Realtime}

Total Kendaraan saat ini :
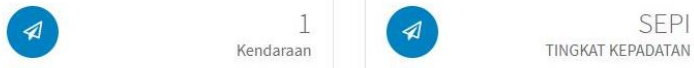

Gambar. 16. Tampilan halaman realtime

Pada halaman ini, user dapat mengetahui tingkat kepadatan lahan parkir secara realtime.

\subsection{Pengujian}

Pada tahap ini, dilakukan pengujian terhadap sistem pendukung keputusan tingkat kepadatan lahan parkir dengan metode Tsukamoto dan konsep IoT. Ada tiga skenario pengujian yang dilakukan pada tahap ini, yaitu pengujian alat, pengujian validasi sistem[7], dan pengujian akurasi sistem. Pengujian alat dilakukan untuk menguji perangkat keras IoT untuk mengambil data. Pengujian validasi sistem menggunakan metode Black Box untuk menguji keseluruhan fungsi sistem. Pengujian akurasi sistem dilakukan untuk menguji akurasi dari metode fuzzy Tsukamoto yang dibuat. Pengujian dilakukan pada server localhost.

\subsubsection{Pengujian Alat}

Pengujian alat dilakukan untuk menguji perangkat keras loT untuk mengambil data. Pengujian dilakukan dengan menguji satu per satu rangkaian alat yang terdiri dari sensor ultrasonik, Arduino UNO, dan WIFI Ethernet Shield.

a. Pengujian fungsionalitas sensor ultrasonik

Pengujian sensor ultrasonik dilakukan dengan menguji apakah sensor ultrasonik dapat mendeteksi adanya objek di depannya atau tidak. Pengujian dilakukan sebanyak 10 kali.

TABLE VII. HASIL UJI SENSOR ULTRASONIK

\begin{tabular}{|c|c|c|c|c|}
\hline $\begin{array}{c}\mathbf{N} \\
\mathbf{0}\end{array}$ & $\begin{array}{c}\text { Jarak } \\
\text { Terbaca }\end{array}$ & $\begin{array}{c}\text { Jarak } \\
\text { Sebenar } \\
- \\
\text { nya }\end{array}$ & $\begin{array}{c}\text { Objek } \\
\text { Terdeteks } \\
\text { i sensor? }\end{array}$ & Keterangan \\
\hline 1 & 10 & 10 & Tidak & Berhasil \\
\hline 2 & 10 & 10 & Tidak & Berhasil \\
\hline 3 & 8 & 10 & Tidak & Berhasil \\
\hline 4 & 4 & 3 & Ada & Berhasil \\
\hline 5 & 8 & 10 & Tidak & Berhasil \\
\hline 6 & 4 & 3 & Ada & Berhasil \\
\hline 7 & 10 & 10 & Tidak & Berhasil \\
\hline 8 & 10 & 10 & Tidak & Berhasil \\
\hline 9 & 9 & 10 & Tidak & Berhasil \\
\hline 10 & 3 & 3 & ada & Berhasil \\
\hline
\end{tabular}


Dari Tabel VII dapat dijelaskan bahwa sensor ultrasonik dapat berfungsi mendeteksi objek dan berdasarkan pengujian dengan 10 data, diketahui bahwa tingkat keberhasilannya yaitu $100 \%$, di mana semua objek dapat terdeteksi.

\section{b. Pengujian fungsionalitas mikrokontroller}

Pada Gambar 21 dapat diketahui bahwa mikrokontroler telah bekerja. Hal ini dilihat dari lampu indikator mikrokontroler yang bekerja. Dengan demikian mikrokontroler lulus pengujian.

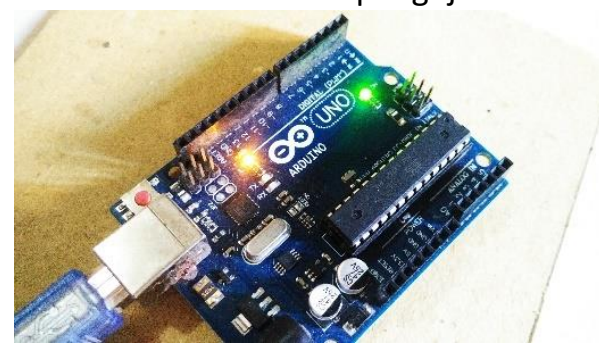

Gambar. 17. Pengujian mikrokontroler

c. Pengujian fungsionalitas WIFI-Ethernet Shield

Pada Gambar 22 dapat diketahui bahwa mikrokontroler telah bekerja. Hal ini dilihat dari lampu indikator Shield yang bekerja. Dengan demikian mikrokontroller lulus pengujian.

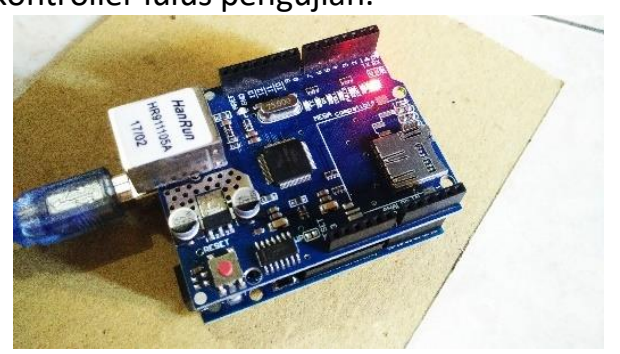

Gambar. 18. Pengujian Ethernet Shield

\subsubsection{Pengujian Akurasi Sistem}

Pengujian validasi sistem pendukung keputusan tingkat kepadatan lahan parkir menggunakan metode Black Box untuk menguji keseluruhan fungsi sistem. Berdasarkan pengujian yang dilakukan, maka hasil pengujian dapat dilihat pada Tabel VIII.

Dari hasil pengujian yang tertera pada Tabel VIII, maka dapat disimpulkan bahwa fungsionalitas sistem pendukung keputusan tingkat kepadatan lahan parkir yang dibuat dapat berfungsi dan menjalankan fungsinya dengan baik dengan tingkat keberhasilan menampilkan informasi $100 \%$. Yaitu, semua halaman untuk kasus uji dapat menampilkan informasi sesuai dengan yang diharapkan sistem.
TABLE VIII. HASIL UJI VALIDASI SISTEM

\begin{tabular}{|c|c|c|}
\hline $\mathbf{N}$ & Nama Kasus Uji & $\begin{array}{c}\text { Status } \\
\text { Validitas }\end{array}$ \\
\hline 1 & Log In berhasil & valid \\
\hline 2 & Log In gagal & valid \\
\hline 3 & Tambah data pendukung \\
keputusan & valid \\
\hline 4 & $\begin{array}{c}\text { Perhitungan derajat keanggotaan } \\
\text { fuzzy }\end{array}$ & valid \\
\hline 5 & Pengolahan rule fuzzy & valid \\
\hline 6 & Perhitungan fuzzy Tsukamoto & valid \\
\hline 7 & Lihat hasil keputusan & valid \\
\hline 8 & Lihat rule base fuzzy & valid \\
\hline 9 & Lihat kondisi lahan parkir & valid \\
\hline 10 & Lihat pola kepadatan lahan parkir & valid \\
\hline
\end{tabular}

\subsubsection{Pengujian Error}

Pengujian akurasi sistem pada penelitian ini dilakukan dengan menghitung persentasi error hasil keluaran sistem. Hasil keluaran sistem yang berupa tingkat kepadatan yang dihitung menggunakan metode fuzzy Tsukamoto dibandingkan dengan tingkat kepadatan sebenarnya pada lahan parkir saat waktu tersebut. Pengujian akurasi dilakukan untuk mengetahui performa dari Sistem Pendukung Keputusan untuk memberikan kepadatan di lahan parkir. Hasil pengujian ini dapat dilihat pada Tabel IX.

TABLE IX. HASIL UJ PEnguJIAN Kepadatan

\begin{tabular}{|c|c|c|c|c|c|}
\hline \multirow{2}{*}{$\begin{array}{c}\mathbf{N} \\
\mathbf{0}\end{array}$} & \multicolumn{2}{|c|}{ Masukan } & \multicolumn{2}{c|}{$\begin{array}{c}\text { Keluaran (Total } \\
\text { Kendaraan) }\end{array}$} & \multirow{2}{*}{ Error (\%) } \\
\cline { 2 - 5 } & Hari & Waktu & $\begin{array}{c}\text { Tot. Ken. } \\
\text { Aktual }\end{array}$ & $\begin{array}{c}\text { Hasil } \\
\text { Fuzzy }\end{array}$ & \\
\hline 1 & Senin & $11: 38$ & 13 & 17 & 21.17 \\
\hline 2 & Senin & $14: 00$ & 23 & 20 & 11.96 \\
\hline 3 & Senin & $17: 36$ & 20 & 20 & 2.35 \\
\hline 4 & Senin & $19: 17$ & 26 & 21 & 19.46 \\
\hline 5 & Selasa & $10: 12$ & 11 & 10 & 6.18 \\
\hline 6 & Selasa & $13: 27$ & 13 & 13 & 0.00 \\
\hline 7 & Selasa & $16: 16$ & 22 & 22 & 0.00 \\
\hline 8 & Selasa & $20: 07$ & 15 & 15 & 0.00 \\
\hline 9 & Rabu & $10: 41$ & 13 & 14 & 6.96 \\
\hline 10 & Rabu & $15: 04$ & 20 & 21 & 5.24 \\
\hline 11 & Rabu & $16: 02$ & 25 & 23 & 9.80 \\
\hline 12 & Rabu & $20: 37$ & 7 & 8 & 9.06 \\
\hline \multicolumn{5}{|c|}{ Rata-rata Error } & \\
\hline
\end{tabular}

Berdasarkan pengujian akurasi yang didapatkan dengan membandingkan hasil dari perhitungan logika fuzzy dengan pengamatan manual sebanyak 12 sampel, dihasilkan error sebesar 8,11\%. Error terbesar dihasilkan dari sampel data pada hari Senin. Hal tersebut karena pada hari Senin adalah awal sistem menghitung pola aturan, di mana jumlah data yang digunakan untuk menentukan pola aturan belum sebanyak pada hari selanjutnya. Nilai error ditentukan 
oleh seberapa banyak data yang digunakan untuk membuat pola aturan fuzzy. Jika semakin banyak data yang digunakan untuk membuat aturan, maka semakin baik pula hasilnya. Saat melakukan pengambilan data, data yang diambil pada hari di mana nilai error yang lebih tinggi tidak sebanyak dengan data yang diambil pada hari yang nilai error-nya lebih kecil. Karena pola aturan fuzzy didapatkan dengan merata-ratakan hasil keluaran fungsi keanggotaan setiap variabel, maka semakin banyak jumlah data yang dihitung nilai rataratanya juga semakin akurat hasilnya. Contohnya seperti pada pengujian untuk hari Selasa. Karena pada hari Selasa dilakukan pengambilan data lebih banyak.

\section{Kesimpulan Dan Saran}

\subsection{Kesimpulan}

Berdasarkan hasil pengujian terhadap Sistem Pendukung Keputusan dalam menentukan tingkat kepadatan lahan parkir, dapat disimpulkan bahwa:

1. IoT diimplementasikan pada miniatur lahan parkir agar sistem dapat secara otomatis terintergrasi dengan lahan parkir. Berdasarkan pengujian fungsionalitasnya, diketahui bahwa perangkat loT yang digunakan dapat melakukan pengambilan data untuk dikirimkan ke server menggunakan koneksi wifi. Persentase keberhasilan alat mengirimkan data yaitu $100 \%$, di mana setiap data yang diambil dapat berhasil dikirimkan ke server. Data yang dikirimkan oleh perangkat sensor berupa sesi adanya kendaraan masuk atau keluar, dan waktu saat sesi tersebut terjadi.

2. Metode Tsukamoto diimplementasikan untuk pengenalan pola aturan kepadatan dan menentukan kepadatan lahan parkir beserta durasi kepadatannya. Berdasarkan pengujian, sistem memiliki error sebesar $8,11 \%$. Besarnya nilai error ditentukan oleh seberapa banyak data yang digunakan untuk membuat pola aturan fuzzy. Karena pola aturan fuzzy didapatkan dengan merata-ratakan hasil keluaran fungsi keanggotaan setiap variabel, maka semakin banyak jumlah data yang dihitung nilai rata-ratanya juga semakin akurat hasilnya.

3. Sistem berbasis web yang dibuat diuji pada server lokal. Berdasarkan hasil pengujian black-box, dapat diketahui bahwa sistem yang menerapkan logika fuzzy dan framework Laravel secara fungsional sudah dapat menghasilkan keluaran yang diharapkan sesuai dengan 10 fungsi yang dibuat di setiap halaman web-nya. Tingkat keberhasilan sistem menampilkan informasi sesuai fiturnya yaitu $100 \%$, di mana seluruh halaman sistem dapat menampilkan informasi sesuai dengan fungsinya. Yaitu dengan menentukan masukan nilai variabel waktu dan total kendaraan untuk menghasilkan keluaran keputusan tingkat kepadatan lahan parkir beserta durasi lamanya kepadatan tersebut berlangsung.

\subsection{Saran}

Hal-hal yang menjadi saran dalam pengembangan sistem ini agar menjadi lebih baik adalah sebagai berikut:

1. Diharapkan untuk pengembangan sistem dalam meningkatkan akurasi, dapat dilakukan dengan menambah jumlah data untuk pengenalan pola aturan dan juga menambah jumlah data untuk pengujian.

2. Diharapkan dapat dibangun Sistem Pendukung Keputusan tingkat kepadatan lahan parkir yang lebih baik lagi dengan menambah fitur seperti: monitoring lahan parkir secara real-time, sistem otomatis untuk alokasi lot parkir, atau lain sebagainya.

\section{DAFTAR PUSTAKA}

[1] A. D. Limantara, Y. C. S. Purnomo dan S. W. Mudjanarko, "Pemodelan Sistem Pelacakan Lot Parkir Kosong Berbasis Sensor Ultrasonic dan Internet of Things (lot) Pada Lahan Parkir Diluar Jalan," Jurnal Universitas Muhammadiyah Jakarta, 2017.

[2] M. I. Mahali, "Smart Door Lock Based on Internet of Things Concept with Mobile Backend as a Service," Jurnal Electronics, Informatics, and Vocational Education (ELINVO), vol. 1, p. 3, 2016.

[3] S. Kusumadewi dan H. Purnomo, Aplikasi Logika Fuzzy Untuk Pendukung Keputusan, Jakarta: Graha IImu, 2004.

[4] B. M. W. \&. C. I. Restuputri, "Optimasi fungsi keanggotaan fuzzy Tsukamoto dua tahap menggunakan algortima genetika pada pemilihan calon penerima beasiswa dan BBP-PPA (studi kasus: PTIIK Universitas Brawijaya Malang)," DORO: Repository Jurnal Mahasiswa PTIIK Universitas Brawijaya, Malang, vol. 5, no. 15, 2015.

[5] D. S. HS, Sistem Penunjang Keputusan, Jakarta: Gunadarma, 1996.

[6] Rudi, I. Dinata dan R. Kurniawan, "Rancang Bangun Prototype Sistem Smart Parking Berbasis Arduino Dan Pemantauan Melalui Smartphone," Jurnal Ecotipe, vol. 4, no. 2, pp. 14-20, 2017.

[7] M. L. Hakim, "Model Smart Parking Berbasis Internet Of Things," 2017. 
[8] E. D. Meutia, "Internet of Things Keamanan dan Privasi," Seminar Nasional dan Expo Teknik Elektro, 2015.

[9] A. N. N. Chamim, "Penggunaan Microcontroller Sebagai Pendeteksi Posisi Dengan Menggunakan Sinyal GSM," Jurnal Informatika, vol. 4, no. 1, 2010.

[10] M. P. T. Sulistyanto, D. A. Nugraha dan N. Sari, "Implementasi loT (Internet of Things) Dalam Pembelajaran di Universitas Kanjuruhan Malang," SMARTICS Journal, vol. 1, no. 1, 2015.

[11] C. A. Aryanto, "Implementasi loT (Internet of Things) Dalam Pembelajaran di Universitas Kanjuruhan
Malang engan Framework Laravel dan Materialize," 2017.

[12] D. Naista, CODEIGNITER VS LARAVEL, Kasus Membuat Website Pencari Kerja, Jakarta: Loko Media, 2017.

[13] N. Yustina, "Sistem Pendukung Keputusan Pemilihan Lensa Kontak Bagi Penderita Kelainan Refraksi Mata Menggunakan Metode Simple Additive Weighting," vol. 1, 2013.

[14] E. Turban, E. J. Aronson dan T. P. Liang, "Decision Support Sistems and Inteligent Sistem, Jilid 1," 2005.

[15] D. J. P. Darat, Perhubungan Darat Dalam Angka 2014, Jakarta: Kementrian Perhubungan RI, 2014. 